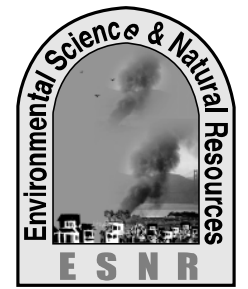

\title{
Gamma Distribution and its Application of Spatially Monitoring Meteorological Drought in Barind, Bangladesh
}

\author{
A. T. M. J. Alam ${ }^{1}$, M. S. Rahman ${ }^{2}$, A. H. M. Saadat ${ }^{1}$ and M. M. Huq ${ }^{2}$ \\ ${ }^{1}$ Department of Environmental Sciences, Jahangirnagar University, Dhaka, Bangladesh \\ ${ }^{2}$ Department of Statistics, University of Rajshahi, Rajshahi, Bangladesh
}

\begin{abstract}
The Barind tract of Bangladesh suffers from frequent drought due to erratic rainfall distribution. In the present study details analysis of rainfall data has been carried out for the years 1971-2010. The Standardized Precipitation Index (SPI) which is followed by gamma distribution is used to evaluate drought vulnerability based on frequency and severity of drought events at multiple time steps (3,5 and 12 months). Drought severity maps are generated in a GIS (Geographical Information System) environment using inverse distance weighting method. Critical (threshold) rainfall values are derived for each station at multiple-time steps in varying drought categories to determine least amount of rainfall required to avoid from drought initiation. The study found that drought vulnerability portrays a very diverse but consistent picture with varying time steps. Analysis and interpretation of the map shows a similar spatial distribution of drought in pre-monsoon season but in monsoon season rainfall deficits shifts its position time to time and occurred in certain discrete pockets. In 12 months period the spatial distribution of drought was almost similar with monsoon season. In pre-monsoon season drought severity was higher in north eastern part of the study area compare to other parts. The study also evident that critical threshold values of rainfall to avoid drought condition was higher in the northern part of high Barind than southern part.
\end{abstract}

Key Words: Barind tract, Drought, Gamma distribution, GIS, Spatial analysis, SPI

\section{Introduction}

Drought is a reoccurring phenomenon in the northwestern part of Bangladesh. Though the drought has attracted less scientific attraction than flood or cyclone, several authors found that the impact of drought can be more defenseless than flood and cyclone (e.g. Brammer, 1987; Shahid and Behrawan, 2008; Shahid, 2008; Alam et al., 2011). This is also evident by the statistics that, in the loss of 1978/79 drought was greater than the loss of flood in 1974 (Paul, 1998). Moreover, Rice production losses in the drought of 1982 were 50 percent more than the losses occur due to the flood in the same year (Ramsey et al., 2007). Furthermore, in the 1997 drought the country reduced 1 million tons of food grains of which 0.6 million tons were T. aman (Ramsey et al., 2007).

On the global level, impact of natural hazards and disasters are staggering. In Bangladesh, the major natural hazards are also in line with global patterns. In the context of global warming, most of the climatic models project a decrease in precipitation in dry season and an increase during monsoon in south Asia (Shahid and Behrawan, 2008). This will cause a crucial combination of more extreme floods and droughts in the region. Due to the land use changes within the country and in neighboring country, Bangladesh has already showed an increased frequency of droughts in recent years (Shahid and Behrawan, 2008). Concern among scientists has grown on changes of precipitation and frequent occurrence of droughts in Bangladesh. Therefore it is necessary to identify drought for taking proper management plan.
The typical approach to gaining a better understanding of the spatial and temporal variability in drought starts with the analysis of rainfall data. Several studies (Sharma and Singh, 2010; Wilks, 1995; Alvarez et al., 2011) cited that gamma distribution is the best fitted model for analyzing annual and seasonal rainfall data. Among the drought indices, Standard precipitation index (SPI) is the most widely used meteorological drought index that follow the gamma distribution. The advantages of SPI are that it can be calculated for a variety of time scales. This versatility allows SPI to monitor short-term water supplies, such as soil moisture which is important for agricultural production, and long-term water resources, such as groundwater supplies, stream flow, and lake and reservoir levels. Soil moisture conditions respond to precipitation anomalies on a relatively short scale (Mishra and Singh 2010). SPI has been used for studying different aspects of droughts, for example, forecasting (Mishra et al., 2007), frequency analysis (Loukas and Vasiliades, 2004; Mishra et al., 2009), spatio temporal analysis (Mishra and Singh, 2009; Shahid, 2008; Y1ldiz, 2009; Bastini, 2011) and climate impact studies (Mishra and Singh, 2009; Loukas et al., 2008), monitoring ground water drought (Shahid and Hazarika, 2010) assessing drought risk (Shahid and Behrawn, 2008).

In the present study, detailed analysis of seasonal and annual drought dynamics has been carried out to identify spatiotemporal drought patterns in Barind region. The study also identifies annual and seasonal critical or threshold value of rainfall that is requires avoiding drought condition. The 
identified critical value of rainfall can be utilized as a planning period for mitigating the impacts of

\section{Calculation of SPI}

McKee et al. (1993, 1995) proposed Standardized Precipitation Index to assess anomalous and extreme precipitation. Since precipitation data are mostly skewed, in order to compute SPI, precipitation data are normalized using gamma function. SPI is based on the probability of precipitation for any desired time scale. In order to compute SPI, historical rainfall data at each station are fitted to gamma probability distribution function:

$$
g(x)=\frac{1}{\rho^{x} \pi(\alpha)} X^{Q-1} e^{\frac{-x}{g}} \quad \text { For } \mathrm{x}>0
$$

Where $\alpha>0$ is the shape parameter, $\beta>0$ is a scale parameter, $x>0$ is the amount of precipitation and $\tau(\kappa)$ defines the gamma distribution

The maximum likelihood solutions are used to optimally estimate the gamma distribution parameters, $\alpha$ and $\beta$ for each station and for each time scale:

$$
\begin{aligned}
& \alpha=\frac{1}{4 A}\left(1+\sqrt{\left.1+\frac{4 A}{3}\right)}\right. \\
& \beta=\frac{x}{\alpha}
\end{aligned}
$$

Where

$$
A=\ln (x)-\frac{2 \ln (x)}{n}
$$

And $n=$ number of precipitation observations. This allows the rainfall distribution at the stations to be effectively represented by a mathematical cumulative probability function given by:

$$
G(x)=\int_{0}^{\infty} g(x) d x=\frac{1}{\beta^{\mathbb{N}} \pi(\alpha)} \int_{0}^{w} x^{\mathbb{E}-1} e^{-x^{x} \beta} d x
$$

Since the gamma function is undefined for $\mathrm{x}=0$ and a precipitation distribution may contain zeros, the cumulative probability becomes:

$$
H(x)=q+(1-q) G(x)
$$

Where, $\mathrm{q}$ is the probability of a zero. The cumulative probability $\mathrm{H}(\mathrm{x})$ is then transformed to the standard normal distribution to yield the SPI (Mckee et al., 1993).

The SPI is computed by dividing the difference between the normalized seasonal precipitation and meteorological drought that manifests as a result of rainfall shortages in the area.

its long-term seasonal mean by the standard deviation. Thus

$$
\mathrm{SPI}=\frac{X_{\mathrm{ij}}-X_{\mathrm{im}}}{\sigma}
$$

Where, Xij is the seasonal precipitation at the ith rain gauge station and $\mathrm{jth}$ observation, Xim the long-term seasonal mean and $\mathrm{s}$ is its standard deviation. Five classes of SPI as shown in Table 1 are used in the present study.

Table 1: Index of drought proneness

\begin{tabular}{lc}
\hline Drought Classes & SPI \\
\hline Extreme Drought & $<-2.00$ \\
\hline Severe Drought & $<-1.5$ \\
\hline Moderate Drought & $<-1.00$ \\
\hline Mild Drought & $<-.00$ \\
\hline No drought & $>0.00$ \\
\hline
\end{tabular}

\section{Results and Discussion}

\section{Three months drought analysis}

Pre-monsoon season of Bangladesh is mainly considered during the period March to May. The present study calculated 3 months drought at the end of May. The time series of SPI value during pre monsoon period is given in figure $1 \mathrm{a}$.

The figure 1a shows that in both pre monsoon seasons the area is affected by different magnitude of drought in about 19 times. But the different parts of the area are affected in different years. The figure also suggests that the frequency of drought has increased in 90s and recent decays compare to $70 \mathrm{~s}$ and $80 \mathrm{~s}$. And it is clear that the study area is affected by drought almost ones in two years. The major drought events in Pre-monsoon season (during 1971-2010) are given figure 2. It is evident that a north-eastern pocket of the study area is more vulnerable to meteorological drought during Premonsoon season. Among these drought events the drought of 1979 was more vulnerable. Where almost all the parts of the study area is affected by drought. The incidences of meteorological drought also partially support the findings of Shahid (2008). Where he found that the major 4 meteorological drought in pre-monsoon was in 1982, 1989, 1992 and 1995 in the western part of Bangladesh. 
(a)

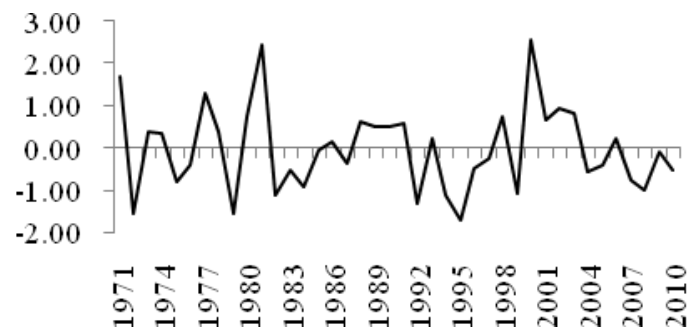

(b)

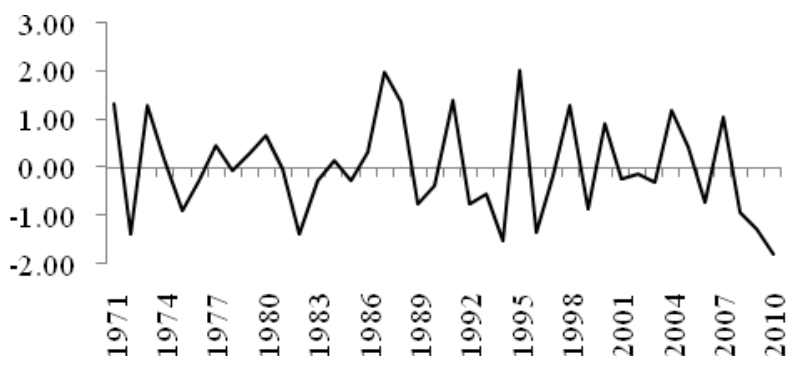

(c)

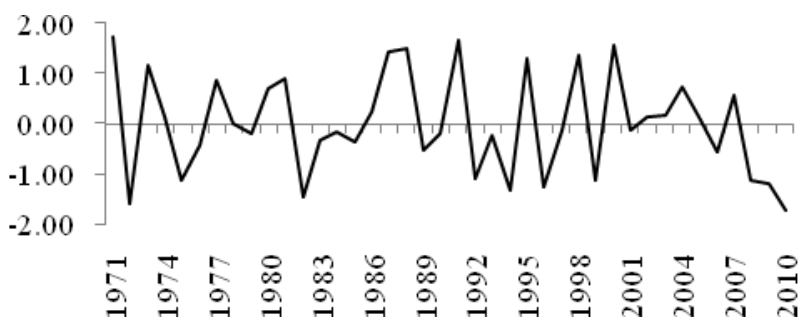

Fig. 1: Time series of average meteorological drought index (a) pre monsoon season (b) Monsoon season (c) 12 months period at the end of December

\section{Five months drought analysis}

In case of monsoon season meteorological drought occurred in different pockets in different years. Unlike pre-monsoon it does not show any similar pattern. Major ten monsoon drought events have been given in the figure 3. Chronic meteorological drought affects the area in the year 1982, 1994 and 2010. Among these drought events the drought of 2010 was most devastating. In addition to this severe drought occur almost all the year cited in the figure 3. However, moderate to mild drought occurred almost every year in some discrete pocket of the study area during 1971-2010.
The drought event of monsoon season also partially supported the result of Shahid (2008) in which he identified 1982, 1989, 1992 and 1995 as the most devastating drought events in the western part of Bangladesh. During the 2006-2010 just within a span five years monsoon drought affect the Barind region 4 times. Shahid (2010) found that the monsoon rainfall in the northwestern part of Bangladesh has increased significantly during the time period 1958-2007. So, this drought event is contradicted with the findings of his study. Other results disagree with the findings of Shahid (2008, 2010) as he stated that there is no significant correlation between rainfall and meteorological drought but all the definition of meteorological 
drought stated that lack of precipitation is the principle cause of meteorological drought (Chopra, 2006; Ramsey et al., 2007). Another result behind the disagreement of the result of Shahid (2008, 2010 ) is that low resolution of rainfall data in his study. He calculated considered only 17 rainfall stations in his study. This low resolution of rain gauge data may give these contradictory results.

\section{Three months drought analysis}

Pre-monsoon season of Bangladesh is mainly considered during the period March to May. The present study calculated 3 months drought at the end of May. The time series of SPI value during pre monsoon period is given in figure $1 \mathrm{a}$.

The figure 1a evident that in both pre monsoon seasons the area is affected by different magnitude of drought in about 19 times. But the different parts of the area are affected in different years. The figure also suggests that the frequency of drought has increased in 90s and recent decays compare to $70 \mathrm{~s}$ and $80 \mathrm{~s}$. And it is clear that the study area is affected by drought almost ones in two years. The major drought events in Pre-monsoon season (during 1971-2010) are given figure 2. It is evident that a north-eastern pocket of the study area is more vulnerable to meteorological drought during Premonsoon season. Among these drought events the drought of 1979 was more vulnerable. Where almost all the parts of the study area is affected by drought. The incidences of meteorological drought also partially support the findings of Shahid (2008). Where he found that the major 4 meteorological drought in pre-monsoon was in 1982, 1989, 1992 and 1995 in the western part of Bangladesh.

\section{Five months drought analysis}

In case of monsoon season meteorological drought occurred in different pockets in different years. Unlike pre-monsoon it does not show any similar pattern. Major ten monsoon drought events have been given in the figure 3. Chronic meteorological drought affects the area in the year 1982, 1994 and 2010. Among these drought events the drought of 2010 was most devastating. In addition to this severe drought occur almost all the year cited in the figure 3. However, moderate to mild drought occurred almost every year in some discrete pocket of the study area during 1971-2010.

The drought event of monsoon season also partially supported the result of Shahid (2008) in which he identified 1982, 1989, 1992 and 1995 as the most devastating drought events in the western part of Bangladesh. During the 2006-2010 just within a span five years monsoon drought affect the Barind region 4 times. Shahid (2010) found that the monsoon rainfall in the northwestern part of Bangladesh has increased significantly during the time period 1958-2007. So, this drought event is contradicted with the findings of his study. Other results disagree with the findings of Shahid (2008, 2010) as he stated that there is no significant correlation between rainfall and meteorological drought but all the definition of meteorological drought stated that lack of precipitation is the principle cause of meteorological drought (Chopra, 2006; Ramsey et al., 2007). Another result behind the disagreement of the result of Shahid (2008, 2010 ) is that low resolution of rainfall data in his study. He calculated considered only 17 rainfall stations in his study. This low resolution of rain gauge data may give these contradictory results.

\section{Twelve months drought analysis}

The average time series of drought events during 12 months period is given in figure $1 \mathrm{c}$. It has been found that among the 40 years period the area has been affected by yearly drought of different magnitude 22 times. The study also observed that last three years of study time consecutively affected by drought (figure 4). Moreover, the spatial distribution of yearly drought pattern is almost similar with the monsoon drought event. Comparing the figure 3 and 4 it is evident that the drought event of 2008, 2009 and 2010 has the almost same spatial distribution in both monsoon and yearly period. The yearly drought map also evident that chronic drought can be occurred in any parts of the study area but does not affect the whole study area at a time. But almost every year some discrete pocket of the area is affected by drought. 


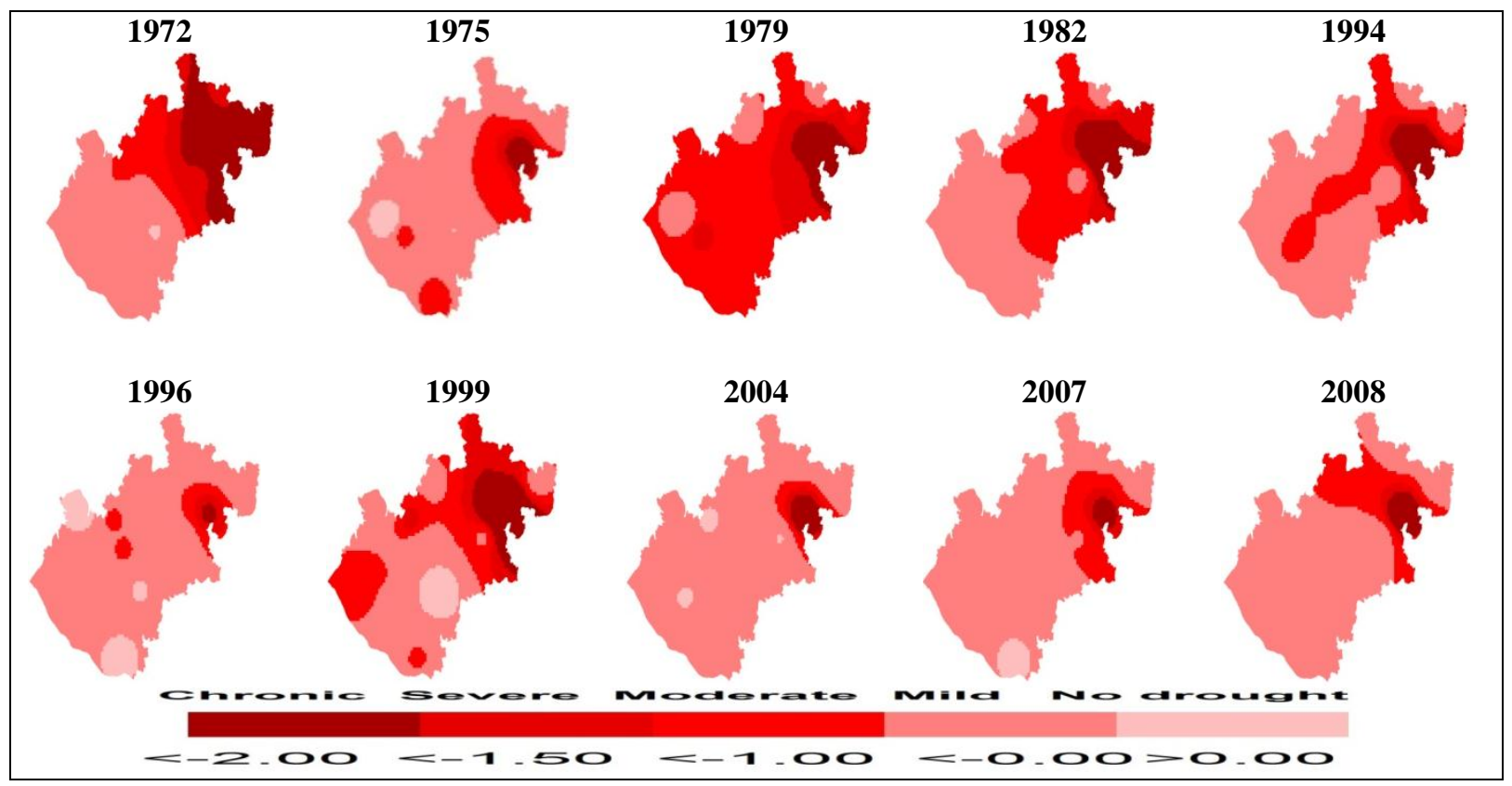

Figure 2: Major meteorological drought events in 3 months period at the end of May

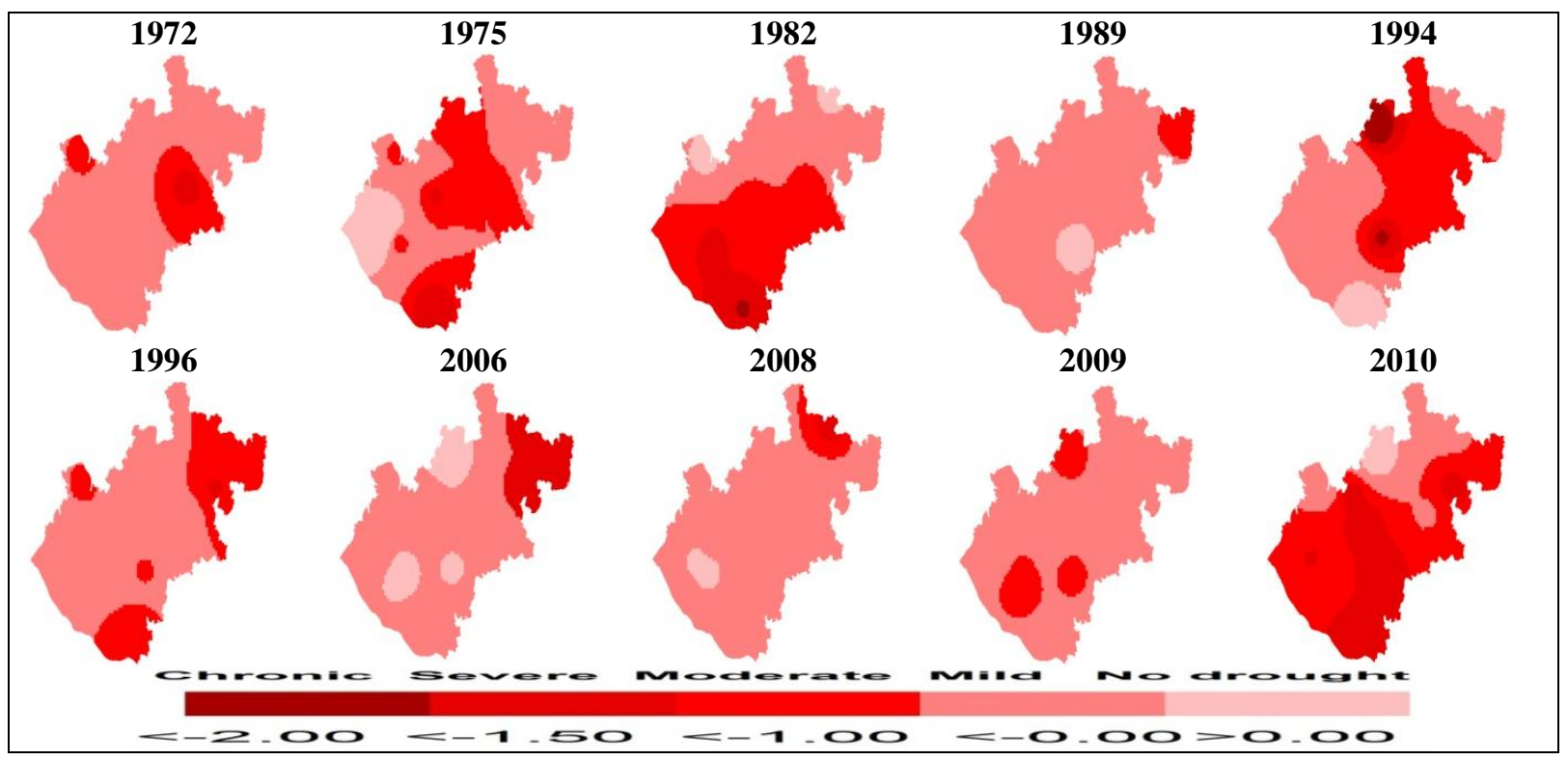

Figure 3: Major meteorological drought events in 5 months period at the end of October

\section{Critical analysis of rainfall}

Critical or threshold rainfall determines the minimum moisture input required for non drought conditions in various time steps. As the SPI values below zero indicate a deficit in rainfall, rainfall corresponding to 0.1 SPI is considered the critical value to avoid drought condition. The critical rainfall values are computed for each station for multiple time steps and then map its spatial distribution. The distribution of rainfall required during 3 months 5 months and 12 months period is given in figure $7 \mathrm{a}, \mathrm{b}$ and $\mathrm{c}$ respectively. The figure shows that a minimum $253 \mathrm{~mm}$ rainfall is required to avoid drought condition in the south western corner of the study area and it require $202 \mathrm{~mm}$ of 
rainfall in north eastern corner during March to May time. The south eastern part requires $1141 \mathrm{~mm}$ of rainfall and northern corner require minimum $1337 \mathrm{~mm}$ rainfall during monsoon (June to October) season. The spatial distribution of 12 months (January to December) critical rainfall show almost similar pattern with monsoon period. This may be because of more than $80 \%$ percent of the rainfall occurring during the monsoon (June to October) period. This is also evident by the Pearson correlation co-efficient test. Where it is found the monsoon SPI is more significantly correlated with yearly SPI than non monsoon SPI. The result of the critical rainfall distribution showed almost similar value with the result of Shahid (2008). Where he mapped that on an average $1250 \mathrm{~mm}$ rainfall is require during rainy season in the northwestern part of Bangladesh, which is the most drought prone area. During pre-monsoon season the average critical rainfall of the north-western Bangladesh was also similar with this study. Shahid (2008) also predict that this critical rainfall is very near to average rainfall which makes the area prone to future chronic drought. The present study also supports this prediction

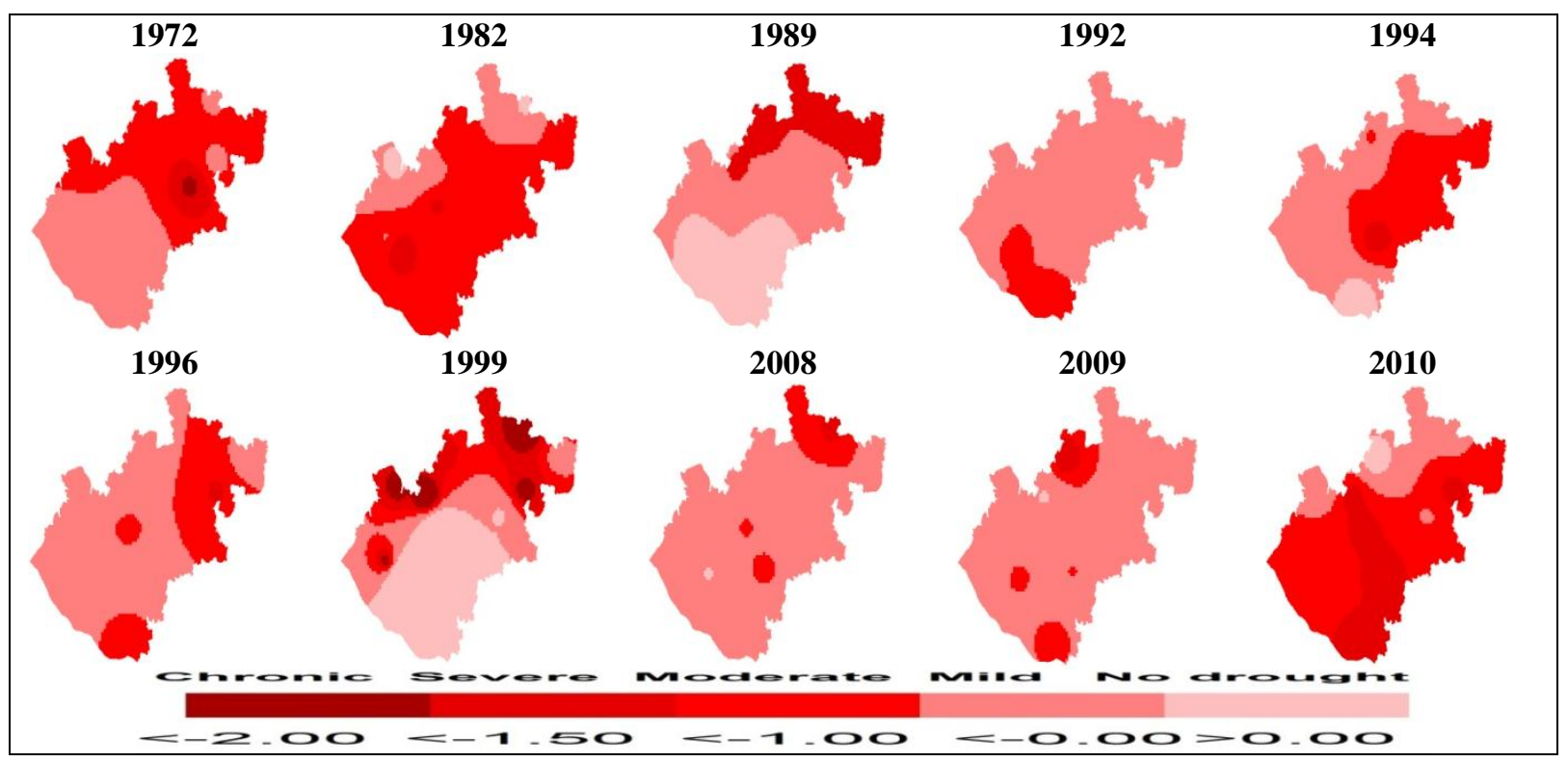

Figure 4: Major meteorological drought events in 12 months period at the end of December

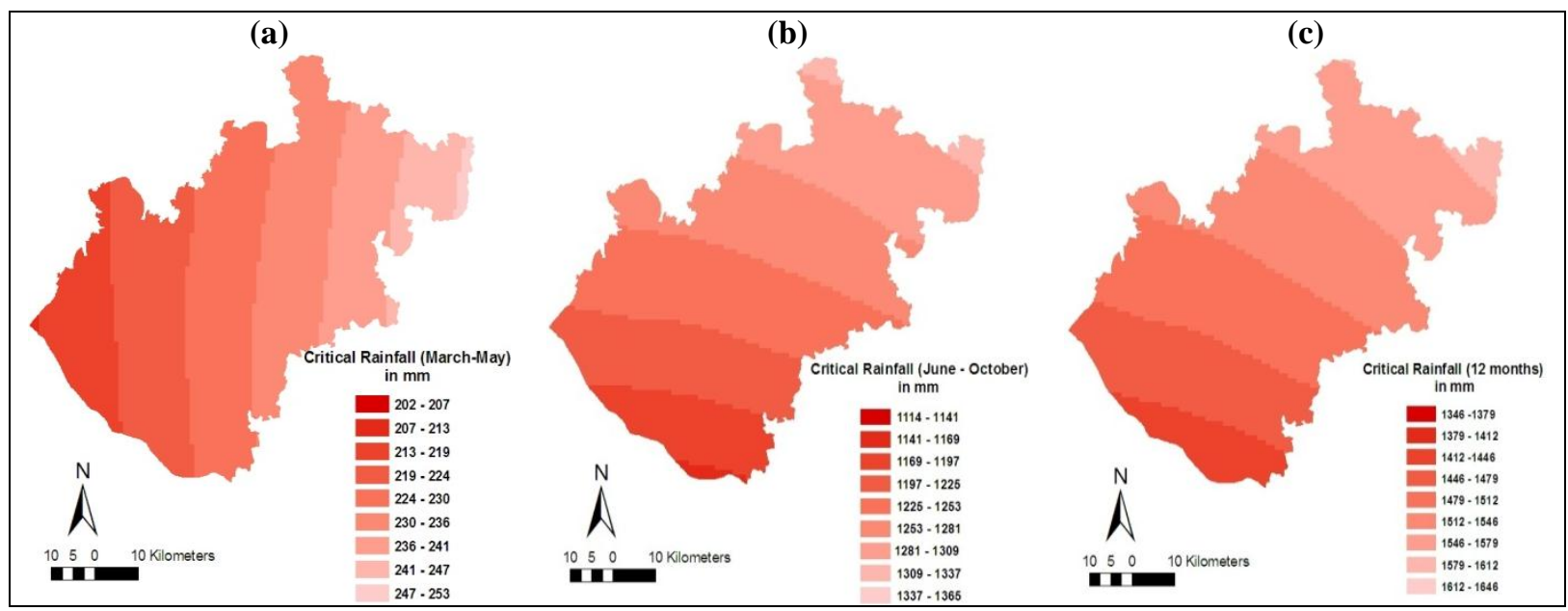

Figure 5: Map showing spatial distribution of threshold rainfall (a) pre monsoon season (b) monsoon season (c) 12 months period 


\section{Conclusion}

In this article a study has been carried out to monitor the drought pattern of Barind region Bangladesh using a well known drought index called standard precipitation index (SPI). The study found that monsoon and yearly drought follow almost a similar spatial distribution in the same year but the magnitude and frequency of drought varies year to year in some discrete pockets. On the other hand pre monsoon drought is focused mostly on the north western corner with higher magnitude. Critical analysis of rainfall also suggests that the area is vulnerable to future chronic drought event. Moreover, it is require higher amount of rainfall in the northern part of the study area to avoid drought

\section{References}

Alam. A. T. M. J.; Saadat A. H. M.; Rahman, M. S., and Barkotulla, M. A. B. 2011. Spatial analysis of rainfall distribution and its impact on agricultural drought at barind region,Bangladesh. Rajshahi University Journal of Environmental Science, 1(1): 40-50.

Alvarez, B. L.; Ferreira, G.; Hube, M. V. 2011. A proposed reparametrization of gamma distribution for the analysis of data of rainfall-runoff driven pollution. Proyecciones Journal of Mathematics, 30(3): 415-439

Batisani, N. 2011. The spatio-temporalseverity dynamics of drought in botswana," Journal of Environmental Protection, 2(6), 803816.

Brammer, H. 1987. Drought in Bangladesh, lessons for planners and administrators, Disasters, 11: 21-29

Chopra, P. 2006. Drought risk assessment using remote sensing and GIS: A case study of Gujrat, An MS thesis submitted to the International Institute for Geoinformation Sciences and Earth Observation, Ensekedl, Netherlands

Loukas, A., and Vasiliades, L. 2004. Probabilistic analysis of drought spatiotemporal characteristics in Thessaly region, Greece, Natural Hazards and Earth System Sciences, 4: 719-731

McKee, T. B.; Doesken, N. J. and Kleist, J. 1993. The relationship of drought frequency and duration to time scales. 8th Conference on Applied Climatology, January, Anaheim, CA, 179-184. pp 17-22
Mishra, A. K. and Singh, V. P. 2010. A review of drought concepts. Journal of Hydrology, 391,202-216.

Mishra, A. K.,; Desai, V. R. and Singh, V. P., 2007. Drought forecasting using a hybrid stochastic and neural network model. J. Hydrologic Eng., ASCE 12 (6); 626-638.

Mishra, A. K., Singh, V. P., 2009. Analysis of drought severity-area-frequency curves using a general circulation model and scenario uncertainty. J. Geophys. Res., 114,D06120. doi:10.1029/2008JD010986.

Mishra, A. K.; Singh, V. P.; Desai, V. R. 2009. Drought characterization: a probabilistic approach. Stoch. Environ. Res. Risk A., 23 (1), 41-55.

Paul, B. K. 1998, Coping mechanisms practiced by drought victims (1994/5) in North Bengal, Bangladesh. Applied Geography, 18,: 355-373.

Ramsey, S.; Subbia, A. R.; Bass, S. and Juergens, I. 2007, Livelihood adaptation to climate variability and change in drought- prone areas of Bangladesh, Asian Disaster Preparedness Center Food and Agriculture Organization of the United Nations.

Shahid, S and Behrawan, H. 2008. Drought riskassessment in the western part of Bangladesh. Nat Hazards, 46:391- 413. DOI 10.1007/s11069-007-9191-5

Shahid, S and Hazarika, M. K., 2010. Groundwater drought in the northwestern districts of Bangladesh, Water Resour Manage, 24:1989-2006, DOI 10.1007/s11269-009-9534-y

Shahid, S, 2008. Spatial and temporal characteristics of droughts in the western part of Bangladesh. Hydrol. Process. 22, 2235-2247. DOI: 10.1002/hyp. 6820

Shahid, S, 2010. Rainfall variability and the trends of wet and dry periods in Bangladesh, Int. J. Climatol., 30:2299-2313.DOI: 10.1002/joc. 2053

Shahid, S. 2011. Impact of climate change on irrigation water demand of dry season Boro rice in northwest Bangladesh. Climatic Change, 105:433-453. DOI 10.1007/s10584-010-9895-5

Sharma, M. A., Singh, J.B. 2010. Use of probability distribution in rainfall analysis. New York Science Journal, 3(9): 40-49

Wilks DS. 1995. Statistical Methods in the Atmospheric Sciences: an Introduction. Academic Press: San Diego, CA. 